\title{
ESTUDO COMPARATIVO DE TÉCNICAS DE SCREENING PARA AVALIAÇÃO DA ATIVIDADE ANTI- BACTERIANA DE EXTRATOS BRUTOS DE ESPÉCIES VEGETAIS E DE SUBSTÂNCIAS PURAS
}

\author{
Everton Giovanni Alves, Adriana Helena Chicharo Vinholis, Luciana Assirati Casemiro, Niege Araçari Jacometti \\ Cardoso Furtado, Márcio Luis Andrade e Silva, Wilson Roberto Cunha e Carlos Henrique Gomes Martins* \\ Núcleo de Pesquisa em Ciências Exatas e Tecnológicas, Universidade de Franca, Av. Dr. Armando Salles Oliveira, 201, \\ 14404-600 Franca - SP, Brasil
}

Recebido em 3/1/07; aceito em 25/9/07; publicado na web em 2/4/08

\begin{abstract}
COMPARATIVE STUDY OF SCREENING TECHNIQUES FOR ANTIBACTERIAL ACTIVITY EVALUATION OF PLANT CRUDE EXTRACTS AND PURE COMPOUNDS. In this work, the effectiveness of four screening techniques (three techniques of the diffusion method and one microdilution broth method) were compared. Evaluated were the ethanolic and dichloromethanic extracts of Miconia rubiginosa (Melastomataceae) against six standard bacteria (ATCC). The results showed statistical disagreement among the three diffusion techniques. Among the diffusion techniques, the well technique displayed the best result. However the microdilution broth method demonstrated to be the most adequate method to evaluate the antibacterial activity of plant crude extracts and pure compounds when compared to the other methodologies.
\end{abstract}

Keywords: antimicrobial activity; screening methods; plant extracts.

\section{INTRODUÇÃO}

Atualmente existem diversas técnicas de screening para definir se o extrato de uma determinada planta possui atividade antimicrobiana, desde as mais simples, que podem ser realizadas rotineiramente, até as mais sofisticadas, que muitas vezes se tornam indisponíveis em alguns laboratórios. Apesar disso, há poucos estudos que relatam qual o melhor método de screening a ser utilizado de acordo com o tipo de extrato a ser testado, mesmo no que se refere às técnicas mais simples. Por vezes, relatos de resultados em diferentes artigos publicados com uma mesma planta são apresentados de maneira distinta em relação à atividade antimicrobiana, às vezes até mesmo discrepantes, mesmo naqueles em que foram utilizadas as mesmas condições de experimento (ex: solvente utilizado para extração, temperatura, tempo de incubação e microrganismos indicadores), embora as técnicas ou modificações empregadas nos métodos de screening para avaliar a atividade antimicrobiana por diferentes autores não tenham sido as mesmas. ${ }^{1}$

Os dois métodos mais comumente utilizados para o screening de extratos de plantas com potencial antibacteriano são o de difusão em ágar e de diluição em caldo. O método de difusão em ágar pode ser realizado através das técnicas do disco, do poço ou template. ${ }^{2-4}$ Diversas modificações já foram realizadas nas metodologias de screening a fim de se obter resultados mais confiáveis, uma vez que alguns fatores, tais como composição do meio de cultura, microrganismos testados, método de extração, $\mathrm{pH}$ e solubilidade das amostras no meio de cultura, podem alterar os resultados, sendo difícil, portanto, padronizar um procedimento. ${ }^{1}$

Quando se utiliza o método de difusão vários fatores podem se tornar fontes de erros, tais como composição do meio de cultura, preparação incorreta do meio de cultura, espessura do meio de cultura, densidade do inóculo incorreta, uso de swab com excesso de caldo para inoculação das placas, temperatura e tempo de incubação inadequados, interações entre o antimicrobiano e o meio de cultura, utilização errada da atmosfera de $\mathrm{CO}_{2}$ quando necessária,

*e-mail: martinsc@unifran.br leitura prematura, erro na medida das zonas de inibição ou uso de culturas mistas ou contaminadas. ${ }^{5}$

O método de difusão em ágar geralmente é utilizado para microrganismos de crescimento rápido e para alguns de crescimento fastidiosos. ${ }^{6}$ Para um resultado confiável dos testes, é preciso trabalhar com uma metodologia padronizada. O método padronizado que é atualmente recomendado pelo NCCLS (atualmente CLSI) se baseia no originalmente descrito por Bauer et al.. ${ }^{7}$

Atualmente, o método de diluição é usado para determinar a concentração mínima de um agente necessário para inibir ou matar um microrganismo. Os procedimentos para determinar a atividade inibitória podem ser realizados tanto pelas técnicas de diluição em caldo ou em ágar. Os agentes antimicrobianos são geralmente testados em diluições consecutivas, e a menor concentração capaz de inibir o crescimento de um organismo é considerada como a Concentração Inibitória Mínima (CIM). ${ }^{8}$ Segundo Andrews, ${ }^{9}$ as CIM's são consideradas excelentes ferramentas para determinar a susceptibilidade dos organismos aos antimicrobianos e, portanto, usadas para julgar a performance de todos os outros métodos de susceptibilidade. Nos laboratórios de diagnóstico, as CIM's são também usadas como uma ferramenta de pesquisa para determinar a atividade in vitro de novos antimicrobianos.

Os métodos de diluição em caldo ou ágar são igualmente aceitáveis para medir quantitativamente a atividade in vitro de um agente antimicrobiano contra um determinado isolado bacteriano. ${ }^{10,11}$ Para realizar o teste preparam-se vários tubos de ensaio ou placas com meio caldo ou ágar, aos quais são acrescentadas diversas concentrações dos agentes antimicrobianos. A seguir, os tubos ou as placas são inoculados com uma suspensão padrão do organismo a ser testado. Após incubação overnight, a $35{ }^{\circ} \mathrm{C}$, examinam-se os testes e determina-se a CIM. A CIM pode ser detectada a "olho nu" ou através de aparelhos baseados em leitura óptica.

A técnica de microdiluição em caldo é uma adaptação da macrodiluição em caldo. É denominada "microdiluição", porque envolve o uso de pequenos volumes de caldo colocados em placas de 80, 96 ou mais poços de fundo redondo ou cônico estéreis, próprias para microdiluição. As placas de microdiluição inoculadas 
devem ser incubadas a $35{ }^{\circ} \mathrm{C}$ por $16-24 \mathrm{~h}$, com no máximo quatro placas em cada pilha, a fim de manter a mesma temperatura de incubação para todas as culturas. ${ }^{11}$ Os fatores primários que influenciam nos valores de CIM no método de diluição em caldo são os mesmos tanto para a técnica de macrodiluição como para de microdiluição, ou seja, a sensibilidade do organismo, o diluente utilizado, o estágio e a taxa de crescimento bacteriano. ${ }^{12}$

O presente estudo teve como objetivo avaliar a eficácia de metodologias de screening comumente usadas em trabalhos que envolvem extratos de espécies vegetais, bem como antimicrobianos padrão (substâncias puras). Foi estudado o método de difusão em ágar pelas técnicas do poço, do disco e do template e o método da microdiluição em caldo. Nos ensaios foram avaliados os extratos etanólico e diclorometânico de Miconia rubiginosa (Melastomataceae) frente às bactérias Staphylococcus aureus, Enterococcus faecalis, Kokuria rhizophila, Escherichia coli, Pseudomonas aeruginosa, e Salmonella typhimurium. As substâncias puras penicilina e gentamicina foram utilizadas na avaliação da atividade frente a bactérias Gram-positivas e Gram-negativas, respectivamente.

\section{PARTE EXPERIMENTAL}

\section{Coleta e identificação do vegetal Miconia rubiginosa}

A espécie vegetal foi coletada numa região do cerrado próximo à Rodovia Tancredo Neves (Franca-SP - Claraval-MG) e uma exsicata (UEC 10830) foi depositada no Departamento de Botânica do Instituto de Biologia da Universidade Estadual de Campinas.

\section{Obtenção e diluição dos extratos}

As partes aéreas do vegetal foram secas e estabilizadas em estufa de ar circulante a $40{ }^{\circ} \mathrm{C}$ e trituradas até a forma de pó em moinho de facas. O pó resultante foi extraído através de maceração, utilizando os solventes diclorometano e etanol por 21 dias. O material líquido resultante foi concentrado em evaporador rotativo. Uma alíquota dos extratos brutos etanólico e diclorometânico foram diluídos em dimetilsulfóxido (DMSO) para obtenção das amostras nas concentrações de 100 e $300 \mathrm{mg} / \mathrm{mL}$, a serem utilizadas para as técnicas do poço, disco e template.

\section{Padronização da densidade do inóculo}

Como a densidade do inóculo influencia no resultado dos experimentos, padronizou-se a quantidade de inóculo a ser utilizada, a fim de assegurar a reprodutibilidade dos ensaios. Inicialmente preparou-se a escala 0,5 de McFarland segundo Bier. ${ }^{13}$ Para isso, adicionou-se $0,5 \mathrm{~mL}$ de cloreto de bário a $1 \%$ em $99,5 \mathrm{~mL}$ de ácido sulfúrico a $1 \%$. Em seguida, transferiu-se $2 \mathrm{~mL}$ dessa suspensão para uma cubeta espectrofotométrica.

Para calibrar a transmitância a 100\% em um espectrofotômetro a um comprimento de onda de $530 \mathrm{~nm}$, utilizou-se água destilada. Em seguida, colocou-se a suspensão 0,5 de McFarland, obtendo a transmitância de $88 \%$. Todas as suspensões bacterianas foram ajustadas na mesma transmitância.

\section{Avaliação da atividade antibacteriana pelo método de difusão em ágar pelas técnicas do disco, poço e template}

Todos os ensaios foram realizados em triplicata utilizando-se cepas provenientes da American Type Culture Collection (ATCC): Staphylococcus aureus (25923), Enterococcus faecalis (29212), Kokuria rhizophila (9341), Escherichia coli (35218), Pseudomonas aeruginosa (27853) e Salmonella typhimurium (14028).

Nas técnicas do disco, poço e template as substâncias puras penicilina $\mathrm{G}$ e gentamicina foram utilizadas também como controle positivo. Para Staphylococcus aureus e Enterococcus faecalis utilizou-se a penicilina $\mathrm{G}$ na concentração de $0,05 \mathrm{mg} / \mathrm{mL}$, enquanto que para Kokuria rhizophila a concentração foi de $0,03 \mathrm{mg} / \mathrm{mL}$. Para Escherichia coli, Salmonella typhimurium e Pseudomonas aeruginosa foi utilizada gentamicina na concentração de $0,05 \mathrm{mg} /$ $\mathrm{mL}$. No método da microdiluição em caldo para determinação da CIM foram utilizadas as mesmas substâncias puras, onde as concentrações avaliadas variaram de 0,0115 a $5,9 \mu \mathrm{g} / \mathrm{mL}$. O antimicrobiano penicilina $\mathrm{G}$ foi preparado em tampão fosfato de potássio a $1 \% \mathrm{pH} 6,0$, enquanto gentamicina foi preparado em água destilada esterilizada. Dimetilsulfóxido foi utilizado como controle negativo para todos os microrganismos.

A determinação da atividade antibacteriana pela técnica do poço foi realizada segundo Grove e Randall, ${ }^{14}$ a qual consiste na utilização de placas com camada dupla (camada base e camada seed de meios adequados ao microrganismo testado). A camada base foi obtida com meio de cultura Agar Mueller Hinton (AMH). Após esterilizado e resfriado a cerca de $50{ }^{\circ} \mathrm{C}$, foram distribuídos $25 \mathrm{~mL}$ em placas de Petri de $25 \times 150 \mathrm{~mm}$ esterilizadas (Pleion (®). A camada seed foi obtida colocando-se em um tubo $12,5 \mathrm{~mL}$ de meio de cultura AMH esterilizado e resfriado a $50{ }^{\circ} \mathrm{C}$, ao qual foi incorporado 2,5 $\mathrm{mL}$ de Caldo Mueller Hinton com o inóculo já preparado. Imediatamente a camada seed foi vertida sobre a camada base. Após a solidificação da camada seed, os poços foram confeccionados com um dispositivo contendo cilindros metálicos esterilizados de 4,0 mm de diâmetro. A seguir, os poços foram completamente preenchidos com $40 \mu \mathrm{L}$ dos extratos a serem testados, além das substâncias puras e o controle negativo. Em seguida foi colocado papel de filtro (Whatman ${ }^{\circledR}$, Inglaterra) esterilizado na tampa de cada placa para reter a água de condensação. Após um período de pré-incubação de $2 \mathrm{~h}$ à temperatura ambiente, que permite a difusão dos extratos antes do início do desenvolvimento dos microrganismos, como preconizado por Möller, ${ }^{15}$ as placas foram incubadas em aerobiose a $36{ }^{\circ} \mathrm{C}$ por $18 \mathrm{~h}$.

$\mathrm{O}$ teste para determinação da atividade antibacteriana pela técnica do disco foi realizado conforme atualizações do CLSI M2A8. Inicialmente foi preparado o meio de cultura AMH. Após resfriamento a cerca de $50{ }^{\circ} \mathrm{C}$, foi transferido um volume de $50 \mathrm{~mL}$ do meio liquefeito para placas de Petri esterilizadas de $25 \times 150$ $\mathrm{mm}$, até atingir a espessura de $4 \mathrm{~mm}$. Com um swab esterilizado, o inóculo foi distribuído uniformemente sobre a superfície do ágar e deixado em repouso à temperatura ambiente durante $3 \mathrm{~min}$. Os discos foram preparados no momento de sua utilização contendo $16 \mu \mathrm{L}$ dos extratos, das substâncias puras e do controle negativo. Após um intervalo de $15 \mathrm{~min}$, as placas foram incubadas em estufa bacteriológica a $36{ }^{\circ} \mathrm{C}$ por $18 \mathrm{~h}$.

A determinação da atividade antibacteriana pela técnica do template foi realizada conforme descrição original da Farmacopéia Brasileira $4^{a}$ edição, ${ }^{16}$ com modificações. Inicialmente foi preparada a camada base para a qual foram transferidos $15 \mathrm{~mL}$ de $\mathrm{AMH}$, previamente esterilizado, para placas de Petri esterilizadas medindo 20 x $100 \mathrm{~mm}$ (Pyrex ®). As placas permaneceram em superfície plana até a solidificação do meio. Para preparação do meio de superfície, o meio de cultura AMH foi previamente esterilizado e mantido em banho-maria a uma temperatura aproximada de $50{ }^{\circ} \mathrm{C}$ até o momento do uso. Em seguida, foram transferidos volumes de $20 \mathrm{~mL}$ do meio fundido a $50{ }^{\circ} \mathrm{C}$ para tubos com tampa de rosca (Pyrex $®)$. Imediatamente foram adicionados a estes tubos $100 \mu \mathrm{L}$ do inóculo previamente preparado, obtendo-o na proporção de $0,5 \%$. Em seguida, o líquido foi vertido na placa de petri contendo a ca- 
mada base. Após a solidificação do meio de superfície, foi colocado um molde de aço inoxidável esterilizado (template) em cada placa. Com auxílio de uma micropipeta, foram adicionados $50 \mu \mathrm{L}$ dos extratos a serem testados, além das substâncias puras e do controle negativo em cada cavidade do template. As placas foram incubadas a $36{ }^{\circ} \mathrm{C}$ por $18 \mathrm{~h}$.

A fim de otimizar a visualização dos halos de inibição da técnica de difusão, foi preparado o revelador cloreto de trifeniltetrazólio (CTT) em gel de ágar bacteriológico a 1\%, onde foram distribuídas $8 \mathrm{~mL}$ da solução em cada placa de $20 \times 100 \mathrm{~mm}$ ou $20 \mathrm{~mL}$ em cada placa de $25 \times 150 \mathrm{~mm}$, após as $18 \mathrm{~h}$ de incubação. As placas foram reincubadas a $37{ }^{\circ} \mathrm{C}$ por $30 \mathrm{~min}$. Os halos de inibição do crescimento bacteriano foram medidos em milímetros, com auxílio de uma régua milimetrada.

\section{Determinação da concentração inibitória mínima (CIM) pela técnica da microdiluição em caldo}

A determinação da concentração inibitória mínima dos extratos foi realizada segundo a metodologia da diluição em caldo (microtécnica) proposta pelo NCCLS, ${ }^{11}$ com as mesmas bactérias utilizadas nas técnicas de difusão em ágar. Foram utilizadas microplacas com fundo em "U" esterilizadas com 96 orifícios $\left(\mathrm{TPP}^{\circledR}, \mathrm{EUA}\right)$. Cada orifício recebeu o inóculo, o meio de cultura líquido $\mathrm{CMH}$ e as soluções dos extratos brutos em concentrações finais que variaram de 50 a $400 \mu \mathrm{g} / \mathrm{mL}$, sendo o volume final de $100 \mu \mathrm{L}$. Logo após a micropipetagem as placas foram tampadas e incubadas a $35^{\circ} \mathrm{C}$ por $24 \mathrm{~h}$, sem agitação. Terminado o período de incubação, foram adicionados em cada orifício das placas $15 \mu \mathrm{L}$ de resazurina a $0,01 \%$ em solução aquosa esterilizada onde, após 4 $\mathrm{h}$ de reincubação, a leitura foi realizada. A resazurina facilita verificar a presença de crescimento microbiano, a coloração azul indica ausência de crescimento microbiano, enquanto a cor vermelha indica a presença de células viáveis em crescimento. Dessa maneira foi possível determinar a menor concentração de cada extrato capaz de inibir o crescimento dos microrganismos indicadores diluídos. Para as substâncias puras, as quais foram também utilizadas como controles positivos, as concentrações avaliadas variaram de 0,0115 a $5,9 \mu \mathrm{g} / \mathrm{mL}$, perfazendo $100 \mu \mathrm{L}$ de volume final. Solução de DMSO no meio de cultura líquido $\mathrm{CMH}$ foi utilizada como controle negativo.

\section{RESULTADOS E DISCUSSÃO}

\section{Comparação entre os halos de inibição das técnicas do disco, poço e template}

Os resultados obtidos com os extratos etanólico e diclorometânico de $M$. rubiginosa após a realização dos ensaios de difusão em ágar pela técnica do poço demonstraram que houve inibição da maioria das bactérias, pela verificação da formação de halos de inibição ao redor dos poços onde foram depositadas as soluções testadas (Tabela 1). Com o objetivo de avaliar se o tamanho do halo de inibição aumentava proporcionalmente ao aumento da concentração do extrato, realizaram-se análises estatísticas de variância seguindo o modelo ONE-WAY ANOVA e teste de Tukey, onde foi evidenciado que, no conjunto dos dados, não houve proporcionalidade entre a concentração dos extratos e o diâmetro do halo de inibição para a maioria dos microrganismos avaliados.

A fim de avaliar se cada método possuía uma precisão adequada, foram calculados os coeficientes de variação a partir das medidas dos halos de inibição, tanto para os extratos como para as substâncias puras (antimicrobianos padrão). Para os extratos, obser- vou-se quem em $75 \%$ das medidas dos halos de inibição utilizando a técnica do template, os coeficientes de variação ficaram abaixo de $5 \%$. Para as técnicas do poço e do disco, respectivamente, 63 e $66 \%$ das medidas ficaram com um coeficiente de variação abaixo de 5\%. Para as substâncias puras observou-se um coeficiente de variação inferior a $5 \%$ para $100 \%$ das medidas quando utilizada a técnica do poço. Para as técnicas do template e do disco, respectivamente, 83,3 e $50 \%$ das medidas ficaram com um coeficiente de variação abaixo de $5 \%$. Isso indica que houve uma precisão significativa entre as medidas dos halos de inibição. ${ }^{17}$

Através dos resultados do ensaio de difusão em ágar pela técnica do disco (Tabela 1), é possível observar que o número de bactérias inibidas pelos extratos foi menor quando comparado à técnica do poço $(\mathrm{p}<0,05)$. Assim como na técnica do poço, as análises estatísticas demonstraram que, no conjunto dos dados, não houve proporcionalidade entre a concentração dos extratos e os diâmetros dos halos de inibição para a maior parte dos microrganismos avaliados. Além disso, na grande maioria das análises que demonstraram proporcionalidade, não havia coincidência com a técnica do poço (Tabela 1).

Ao contrário das técnicas do poço e do disco, os resultados obtidos na realização dos ensaios de difusão em ágar pela técnica do template demonstraram que houve inibição apenas de uma pequena parte das bactérias. Fica evidente que dentre as três técnicas de difusão em ágar analisadas, a do template foi a que demonstrou o menor número de halos de inibição, embora nesta técnica a quantidade de extrato aplicada na placa tenha sido maior. Considerando as outras duas técnicas, fica evidente pelos resultados alcançados que a do poço se mostrou mais satisfatória para detecção da atividade antibacteriana das amostras avaliadas por propiciar a maior facilidade de contato entre estas e os microrganismos testados.

A Tabela 1 também apresenta os resultados da análise estatística seguindo o modelo ONE-WAY ANOVA e teste de Tukey (significância de 5\%), comparando as medidas dos halos de inibição obtidos pelas diferentes técnicas de difusão em ágar: poço, disco e template. Os resultados obtidos com extrato etanólico nas duas concentrações frente a $E$. faecalis, E. coli e P. aeruginosa evidenciam que houve diferença estatística significante entre as técnicas do poço e do disco nas concentrações testadas $(\mathrm{p}<0,05)$. No caso de $S$. aureus, observou-se que não houve diferença estatisticamente significante entre os halos de inibição da técnica do poço e do disco para o extrato etanólico. Para $K$. rhizophila e $S$. typhimurium, os halos de inibição apresentados pelo extrato etanólico foram estatisticamente semelhantes entre as técnicas do disco e do poço somente na concentração de $300 \mathrm{mg} / \mathrm{mL}$.

Como na técnica do template não houve formação de halos de inibição para grande parte dos microrganismos testados, houve diferença estatística entre a maioria dos halos medidos quando comparados à técnica do poço, sendo semelhantes somente na concentração de $300 \mathrm{mg} / \mathrm{mL}$ contra $K$. rhizophila.

Os halos de inibição foram estatisticamente semelhantes entre as técnicas do template e do disco para o extrato etanólico na concentração de $300 \mathrm{mg} / \mathrm{mL}$ frente a $K$. rhizophila e para concentrações de 100 e $300 \mathrm{mg} / \mathrm{mL}$ contra E. coli.

Em relação ao extrato diclorometânico de $M$. rubiginosa, foi possível observar que houve diferença estatisticamente significativa entre os halos de inibição das técnicas do poço e do disco para as concentrações testadas $(\mathrm{p}<0,05)$, só havendo semelhança estatística entre as técnicas, na concentração de $300 \mathrm{mg} / \mathrm{mL}$ frente a $S$. aureus. Além disso, foi possível observar que para E. coli o extrato diclorometânico apresentou halos de inibição pela técnica do poço, o que não ocorreu na técnica do disco.

Assim como observado para o extrato etanólico, o extrato 


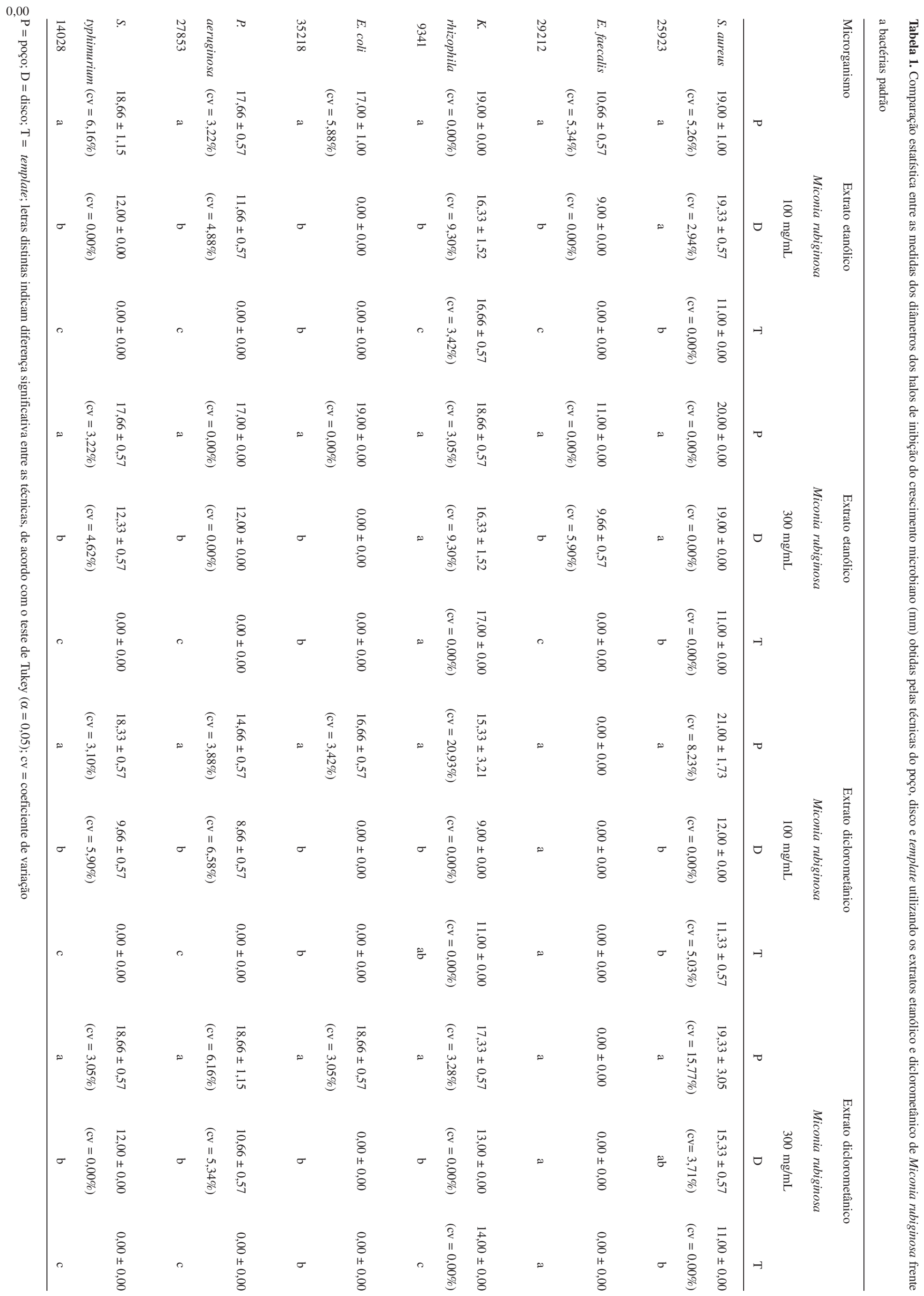


diclorometânico não produziu halos de inibição para grande parte dos microrganismos testados, quando foi utilizada a técnica do template. Houve diferença estatística entre a maioria das medidas dos halos de inibição quando comparadas à técnica do poço $(\mathrm{p}<0,05)$, sendo semelhantes apenas nas concentrações de $100 \mathrm{e}$ $300 \mathrm{mg} / \mathrm{mL}$ contra E. faecalis.

Os halos de inibição medidos na técnica do template quando comparados à do disco mostraram semelhança estatística para o extrato diclorometânico nas concentrações de 100 e 300 mg/mL contra S. aureus, E. faecalis e E. coli e na concentração de $100 \mathrm{mg} /$ $\mathrm{mL}$ contra $K$. rhizophila $(\mathrm{p}<0,05)$.

O solvente DMSO utilizado como controle negativo nas três técnicas não apresentou nenhuma atividade antimicrobiana frente a qualquer microrganismo testado, enquanto as substâncias puras, as quais foram também utilizadas como controles positivos, mostraram halos de inibição frente a todas as bactérias, demonstrando a efetividade das técnicas (Tabela 2). Entretanto, deve-se considerar que a avaliação da atividade antimicrobiana de substâncias puras está sujeita a um menor número de interferentes quando comparada à avaliação da atividade de amostras complexas, como os extratos brutos de espécies vegetais, pois o conhecimento das características físico-químicas do agente antimicrobiano, como solubilidade, carga iônica e massa molecular, possibilita evidenciar possíveis interferências que possam ser causadas por constituintes desconhecidos presentes nas amostras. A atividade da gentamicina, por exemplo, é influenciada pela presença de magnésio no meio de cultura, enquanto que a atividade da penicilina é influenciada pelo $\mathrm{pH}$ do meio. ${ }^{18}$

Observando-se os resultados obtidos na avaliação da atividade antimicrobiana das substâncias puras, pelo método de difusão em ágar utilizando-se as três técnicas, percebe-se que a quantidade de substância aplicada na placa não foi o fator preponderante para a formação dos halos de inibição, pois se assim fosse, a utilização do template possibilitaria a obtenção de maiores halos de inibição em todos os experimentos. A técnica utilizada na avaliação da atividade exerce influência direta na formação do halo de inibição. Como exemplo, pode-se citar as polimixinas, as quais são grandes peptídeos cíclicos, que por difundirem muito pouco produzem pequenos halos de inibição, mesmo quando microrganismos altamente sensíveis são testados contra uma alta concentração do antibiótico. ${ }^{18}$

\section{Técnica da microdiluição em caldo para determinação da concentração inibitória mínima (CIM)}

A Tabela 3 apresenta as concentrações inibitórias mínimas (CIM's) dos extratos etanólico e diclorometânico de M. rubiginosa, obtidas pelo método de microdiluição em caldo. As CIM's variaram entre 250 e $>400 \mu \mathrm{g} / \mathrm{mL}$ frente aos microrganismos testados. Observa-se que os extratos apresentaram atividade antibacteriana contra todos os microrganismos testados, embora para S. aureus a CIM tenha sido superior a $400 \mu \mathrm{g} / \mathrm{mL}$. As sustâncias puras avaliadas, as quais foram também utilizadas como controles positivos, foram capazes de inibir o crescimento microbiano em baixas concentrações.

Os valores de CIM foram determinados pela leitura visual após revelação com resazurina, é um indicador de óxido-redução que

Tabela 3. Concentração inibitória mínima (CIM) dos extratos etanólico e diclorometânico de Miconia rubiginosa

\begin{tabular}{lccc}
\hline Microrganismos/ATCC & CIM $(\mu \mathrm{g} / \mathrm{mL})$ & \\
& $\begin{array}{c}\text { Extrato } \\
\text { etanólico } \\
\text { Miconia } \\
\text { rubiginosa }\end{array}$ & $\begin{array}{c}\text { Extrato diclo- } \\
\text { rometânico de } \\
\text { Miconia } \\
\text { rubiginosa }\end{array}$ & $\begin{array}{c}\text { Substância } \\
\text { pura }\end{array}$ \\
\hline S. aureus / 25923 & $>400$ & $>400$ & $0,18^{*}$ \\
E. faecalis / 29212 & 400 & 400 & $0,36^{*}$ \\
K. rhizophila / 9341 & 300 & 300 & $0,02^{*}$ \\
E. coli / 35218 & 400 & 400 & $2,95^{\#}$ \\
P. aeruginosa / 27853 & 250 & 250 & $2,95^{\#}$ \\
S. typhimurium / 14028 & 300 & 350 & $1,47^{\#}$ \\
\hline
\end{tabular}

* Penicilina; "Gentamicina

Tabela 2. Comparação estatística entre as medidas dos diâmetros dos halos de inibição do crescimento microbiano (mm) obtidas pelas técnicas do poço, disco e template utilizando substâncias puras frente a bactérias padrão

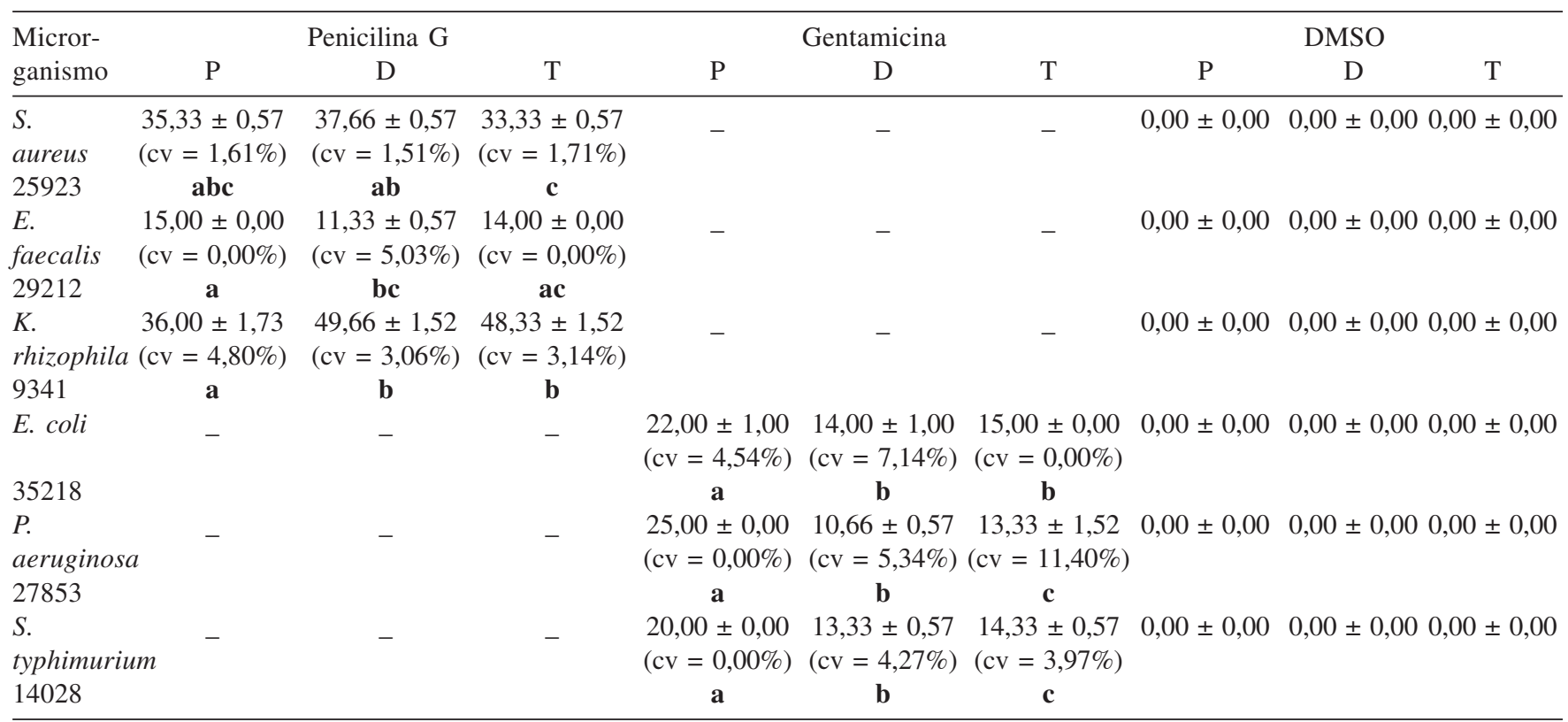

$\mathrm{P}=$ poço; $\mathrm{D}=$ disco; $\mathrm{T}=$ template $;$ _: Não avaliado; Letras distintas indicam diferença significativa entre as técnicas, de acordo com o teste de Tukey $(\alpha=0,05)$; cv = coeficiente de variação 
tem sido utilizado para avaliar a viabilidade de células microbianas. ${ }^{19}$ A resazurina (7-hidroxi-3H-fenoxazina-3-ona-10-óxido) de cor azul é oxidada na presença de células viáveis a resofurina, substância de coloração vermelha. ${ }^{20}$

Não foi possível comparar os resultados obtidos pela técnica da microdiluição em caldo, já que ainda não foram publicados trabalhos demonstrando as CIM's de extratos de M. rubiginosa.

Ao contrário do método de microdiluição em caldo, alguns extratos não apresentaram atividade antibacteriana quando foram utilizados os métodos de difusão. Esses resultados talvez possam ser explicados pela dificuldade de difusão do extrato no meio de cultura. Bandeira et $a l .{ }^{21}$ observaram que a dificuldade de difusão de produtos naturais pode estar relacionada à sua hidrossolubilidade e à sua massa molecular. Essas afirmações estão de acordo com Rios et al., ${ }^{1}$ que argumentaram que as pesquisas sobre atividade antimicrobiana de extratos de plantas e de substâncias isoladas encontram problemas devido à característica lipofílica de algumas amostras.

Celloto et al. ${ }^{22}$ avaliaram a atividade antimicrobiana de extratos etanólico, hexânico e diclorometânico de Miconia rubiginosa utilizando a técnica do poço. Observaram que o extrato etanólico em uma concentração de $300 \mathrm{mg} / \mathrm{mL}$ foi o mais ativo, inibindo a bactéria Gram-positiva $S$. aureus (ATCC 25923), o que coincide com os nossos resultados. O mesmo efeito não foi observado para o extrato etanólico frente à bactéria Gram-negativa $P$. aeruginosa (ATCC 27853), que não demonstrou atividade antimicrobiana, ao contrário de nosso estudo. A contradição entre os resultados talvez possa ser explicada pela densidade do inóculo, já que a mesma não foi ajustada por espectrofotometria no estudo de Celloto et al..$^{22} \mathrm{e}$ se constitui em uma variável que influencia nos testes de difusão.

Segundo Auricchio et al., ${ }^{23}$ quando se comparam estudos de atividade antimicrobiana de extratos de plantas medicinais, é notória a dificuldade de comparação entre os resultados, pois as variáveis vão dos aspectos climáticos que exercem influência na composição química, como o estágio de desenvolvimento do vegetal quando da sua coleta, parte da planta estudada, forma de preparar o material para estudo e, principalmente, os protocolos seguidos nos experimentos.

Rios et al., ${ }^{1}$ na tentativa de solucionar a falta de uniformidade nos critérios de seleção para o estudo da atividade antimicrobiana de plantas medicinais, propuseram métodos padrão usados para o estudo de extratos de plantas e de óleos essenciais, bem como de seus compostos isolados, sendo estes os métodos de difusão, diluição e bioautografia.

Em uma revisão recente de artigos publicados sobre atividade antimicrobiana de plantas medicinais, Rios e Recio ${ }^{24}$ revelaram que o maior problema com as pesquisas ainda continua sendo a falta de uniformidade nos critérios selecionados para estudar a atividade. Isso freqüentemente leva a relevantes contradições entre os resultados obtidos por diferentes grupos e até para o mesmo autor estudando a mesma amostra com diferentes métodos.

\section{CONCLUSÕES}

Quando comparados os resultados da atividade antibacteriana dos extratos brutos e substâncias puras utilizando-se o método de difusão em ágar observou-se que houve discordância estatisticamente significante entre as três técnicas de screening analisadas, sendo que o ensaio de difusão em ágar pela técnica do poço demonstrou melhor performance, já que houve inibição da maioria das bactérias testadas. Embora essa tenha sido a melhor técnica de difusão observada nesse estudo, pode-se considerar que o método de diluição em caldo foi a melhor opção para se determinar a atividade antimicrobiana.

\section{REFERÊNCIAS}

1. Rios, J. L.; Recio, M. C.; Villar, A.; J. Ethnopharmacol. 1988, 23, 127.

2. Chand, S.; Lusunzi, I.; Veal, D. A.; Willians, L. R.; Karuso, P.; J. Antibiot. 1994, 47, 1295.

3. Furtado, N. A. J. C.; Tese de Doutorado, Universidade de São Paulo, Brasil, 2004.

4. Cordeiro, C. H. G.; Sacramento, L. V. S.; Corrêa, M. A.; Pizzolitto, A. C.; Baub, T. M.; Braz. J. Pharm. Sci. 2006, 42, 395.

5. Silva, C. H. P. M.; Bacteriologia: Um Texto Ilustrado, Ed. Eventos: Teresópolis, 1999.

6. Erna, C. T.; Rev. Chil. Infect. 2002, 19, 77.

7. Bauer, A. W.; Kirby, W. M. M.; Sherris, J. C.; Turk, M.; Am. J. Clin. Pathol. 1966, 45, 493.

8. Murray, P. R.; Manual of Clinical Microbiology, $7^{\text {th }}$ ed., ASM Press: Washington, 1999.

9. Andrews, J. M.; J. Antimicrob. Chemother. 2001, 48, 5.

10. Doern, G. V.; Tubert, T. A.; Antimicrob. Agents Chemother. 1988, 32, 259.

11. National Committee for Clinical Laboratory Standard; Methods for Dilution Antimicrobial Susceptibility Tests for Bacteria That Grow Aerobically, Approved Standard - M7-A6, ed 6, vol. 23, 2003.

12. Chiristofilogiannis, P.; Aquaculture 2000, 196, 297.

13. Bier, O.; Bacteriologia e imunologia: em suas aplicações à medicina e à higiene, Ed. Melhoramentos: São Paulo, 1981.

14. Grove, D. C.; Randall, W. A.; Assay Methods of Antibiotic: a Laboratory Manual, Medical Encyclopedia: New York, 1955.

15. Möller, A. J. R.; Odontol. Tidskr. 1966, 74, 1.

16. Farmacopéia Brasileira, Atheneu: São Paulo, 1988.

17. Esmerino, L. A.; Pereira, A. V.; Adamowicz, T.; Borges, D. M.; Talacimon, E. A.; Schelesky, M. E.; Biol. Health Sci. 2004, 10, 53.

18. Greenwood, D.; Antimicrobial Chemotherapy, $2^{\text {nd }}$ ed., Oxford University: Oxford, 1989

19. Montejano, H. A.; Gervaldo, M.; Bertolotti, S. G.; Dyes Pigm. 2005, 64, 117.

20. Palomino, J. C.; Martin, A.; Camacho, M.; Guerra, H.; Swings, J.; Portaels, F.; Antimicrob. Agents Chemother. 2002, 46, 2720.

21. Bandeira, M. F. C. L.; Oliveira, M. R. B.; Pizzollito, A. C.; Benatti Neto, C.; J. Bras. Clin. Est. Odontol. 1998, 3, 46.

22. Celloto, A. C.; Nazario, D. Z.; Spessoto, M. A.; Martins, C. H. G.; Cunha, W. R.; Braz. J. Microbiol. 2003, 34, 339.

23. Auricchio, M. T.; Bacchi, E. M.; Rev. Inst. Adolfo Lutz 2003, 62, 55.

24. Rios, J. L.; Recio, M. C.; J. Ethnopharmacol. 2005, 100, 80. 